\title{
Efficient optimization of nickel-cerium interface by constructing ethylene glycol ligand environment for fast water oxidation reaction kinetics
}

\author{
Changhong Zhan ${ }^{1}$, Zijia $\mathrm{Yu}^{1}$, Zheng Liu ${ }^{1}$, Yong $\mathrm{Chen}^{1}$, Delun Chen ${ }^{1}$, Jinchun $\mathrm{Tu}^{1^{*}}$, Qiang $\mathrm{Wu}^{2^{*}}$, \\ Xiaolin Zhang ${ }^{3^{*}}$ and Yang Cao ${ }^{1,3}$
}

\begin{abstract}
As a half-reaction to obtain high-efficiency and stable water-splitting, oxygen evolution reaction (OER) is a slow-kinetics process involving a four-electron $\left(4 \mathrm{e}^{-}\right)$transfer process and therefore requires catalysts to fasten electron transfer. Here, we rationally optimized an interface material of ceria nanoparticles and nickel hydroxide by adsorbing ethylene glycol (EG-Ni(OH) $\left.)_{2} \mathrm{CeO}_{2}\right)$, which produced ultrasmall nanosheets uniformly attached onto carbon cloth substrate. According to the characterization and density functional theory (DFT), the ethylene glycol-induced nickelcerium interface had strong electron interaction, generating numerous of $\mathrm{Ni}^{(3-\delta)+}$ active sites, reducing the energy reaction barrier, and promoting the electron-transport kinetics in the catalytic system. EG-Ni(OH) $)_{2} @ \mathrm{CeO}_{2}$ showed excellent OER performance, with a low overpotential $(335 \mathrm{mV})$ at $50 \mathrm{~mA} \mathrm{~cm}^{-2}$ and a small Tafel slope $\left(67.4 \mathrm{mV} \mathrm{dec}^{-1}\right)$. And the $\mathrm{EG}-\mathrm{Ni}(\mathrm{OH})_{2} @ \mathrm{CeO}_{2}$ also maintained stable for up to $60 \mathrm{~h}$ at 10 , 20 , and $30 \mathrm{~mA} \mathrm{~cm}^{-2}$. Overall, this research shows the significance of the interface engineering of metal materials based on organic-solvent adsorption to improve the electrocatalytic OER process.
\end{abstract}

Keywords: ethylene-glycol ligand, nickel-cerium interface, $\mathrm{Ni}^{(3-\delta)+}$, oxygen evolution reaction

\section{INTRODUCTION}

The global energy crisis has sparked the research and development related to high-performance energy conversion and storage devices [1-6]. Electrocatalytic water splitting into hydrogen and oxygen is an attractive path for developing sustainable energy [7-9]. However, the capacity of water splitting is severely restricted by the weak kinetics of the oxygen evolution reaction (OER) [10-13]. OER is a complicated process that involves a four-electron $\left(4 \mathrm{e}^{-}\right)$transfer and requires high oxygen evolution overpotentials and fast electron transfer rate [14-18]. Iridium oxide $\left(\mathrm{IrO}_{2}\right)$ and ruthenium oxide $\left(\mathrm{RuO}_{2}\right)$ have been known as the most active anodic semireactive OER catalysts of the electrocatalytic water splitting, but their scarcity and high cost largely limit their wide applications $[19,20]$. Thus, great efforts have been input toward ascertaining their non-precious alternatives.

The use of earth-abundant $3 \mathrm{~d}$ metals as OER catalysts in place of noble metals has been proven suitable [21-24]. Among them, nickel oxide and nickel hydroxide exhibit promising OER activities but undergo weak electroconductivity [25-29]. Recently, some research teams reported significant improvement of the OER performance for oxygen generation via incorporating $\mathrm{NiO}$ and $\mathrm{Ni}(\mathrm{OH})_{2}$ with impurity elements (namely, doping impurity elements [Fe [30], Co [31,32], Mo [33,34], and Ce $[35,36]])$ or constructing heterogeneous structures between impurity materials and Ni-based catalysts [37-39]. Zhao et al. [40] synthesized $\mathrm{Ni}_{x} \mathrm{Ce}_{y} @ \mathrm{CP}$ on carbon paper, in which the tight interface induced by the strong electron interaction between the interfaces involved the adjustment of the bond strength between the intermediate and the catalyst to enhance the conductivity of $\mathrm{Ni}(\mathrm{OH})_{2}$. The distribution of ions and water at the interface would strongly affect the OER kinetic process and the electron

\footnotetext{
${ }^{1}$ State Key Laboratory of Marine Resource Utilization in South China Sea; School of Materials Science and Engineering, Hainan University, Haikou 570228, China

${ }^{2}$ School of Tropical Medicine and Laboratory Medicine; Key Laboratory of Emergency and Trauma of Ministry of Education \& Research Unit of Island Emergency Medicine of Chinese Academy of Medical Sciences, Hainan Medical University, Haikou 571199, China

${ }^{3}$ Qiongtai Normal University, Haikou 571127, China

* Corresponding authors (emails: tujinchun@hainu.edu.cn (Tu J); wuqiang001001@aliyun.com (Wu Q); xlzhang0812@gmail.com (Zhang X))
} 
transfer process [41].

Herein, we demonstrated a strategy that utilized unique ethylene-glycol (EG) ligand environments for efficient interfacial OER to enhance the kinetic catalysis. After being liganded by EG, the nickel-cerium (EG-Ni(OH) $\mathrm{CeO}_{2}$ ) nanosheets showed excellent OER performance with a low overpotential $(335 \mathrm{mV})$ at $50 \mathrm{~mA} \mathrm{~cm}^{-2}$ and a small Tafel slope $\left(67.4 \mathrm{mV} \mathrm{dec}^{-1}\right)$. X-ray photoelectron spectroscopy (XPS) and electrochemical oxidation peaks indicated that the ethylene oxide-doped cerium oxide and nickel hydroxide formed a nanointerface, greatly increased the number of $\mathrm{Ni}^{(3-\delta)+}$ active sites and the conversion of $\mathrm{Ni}^{2+} \rightarrow \mathrm{Ni}^{3+}$ during the electrochemical reaction, and consequently reduced the Tafel slope considerably and increased the rate of reaction kinetics. Density functional theory (DFT) demonstrated that the catalytic barrier was predicted to have optimally lowered down OER intermediates $\left(\mathrm{OH}^{\star}, \mathrm{O}^{*}\right.$, and $\left.\mathrm{OOH}^{*}\right)$ by forming the vast $\mathrm{Ni}^{(3-\delta)+}$ site on EG-adsorbed nickel-cerium interface. Moreover, the EG- $\mathrm{Ni}(\mathrm{OH})_{2} @ \mathrm{CeO}_{2}$ nanosheets had acceptable durability even after $60 \mathrm{~h}$ under 10,20, and $30 \mathrm{~mA} \mathrm{~cm}^{-2}$. The high OER performance manifests the importance of interface engineering according to organicsolvent adsorption in designing OER electrocatalysts.

\section{EXPERIMENTAL SECTION}

\section{Chemicals and reagents}

Nickel acetylacetonate $\left(\mathrm{Ni}(\mathrm{acac})_{2}\right)$, cerium nitrate $\left(\mathrm{Ce}\left(\mathrm{NO}_{3}\right)_{3}\right)$, and $n$-butylamine $\left(\mathrm{C}_{4} \mathrm{H}_{11} \mathrm{~N}\right)$ were purchased from Shanghai Aladdin Bio-Chem Technology Co., LTD. Methanol $\left(\mathrm{CH}_{3} \mathrm{OH}\right)$ was purchased from Xilong Scientific Co., LTD. Carbon cloth (CC) was purchased from Phychemi Hong Kong Company Limited. All reagents were used as-received without further purification.

\section{Catalyst preparation}

The typical synthesis of EG- $\mathrm{Ni}(\mathrm{OH})_{2} @ \mathrm{CeO}_{2}$ was proceeded as follows. CC $(2.5 \mathrm{~cm} \times 2 \mathrm{~cm})$ was sonicated in acetone, ethyl alcohol, and deionized water for $20 \mathrm{~min}$ and then dried for use. Next, $0.3 \mathrm{mmol}$ of $\mathrm{Ni}(\mathrm{acac})_{2}$ and $0.075 \mathrm{mmol}$ of $\mathrm{Ce}\left(\mathrm{NO}_{3}\right)_{3} \cdot 6 \mathrm{H}_{2} \mathrm{O}$ were mixed in a solution (30 mL of methanol $+0.3 \mathrm{~mL}$ of $n$-butylamine) to form a suspension. The suspension and dry CC were ultrasonicated for $30 \mathrm{~min}$, and then transferred to a $50-\mathrm{mL}$ Teflon-linked steel autoclave heated up to $170^{\circ} \mathrm{C}$ for $10 \mathrm{~h}$. Afterwards, the CC was rinsed thrice with ethyl alcohol and subsequently dried at room temperature for further use.

The prepared sample was placed in a three-necked flask containing $100 \mathrm{~mL}$ of EG and reacted at $150^{\circ} \mathrm{C}$ for $12 \mathrm{~min}$ in an atmospheric pressure microwave $(800 \mathrm{~W})$, cooled to room temperature, and rinsed with ethanol to obtain EG$\mathrm{Ni}(\mathrm{OH})_{2} @ \mathrm{CeO}_{2}$. The synthesis of EG-Ni(OH$)_{2}$ was similar to that of EG-Ni(OH $)_{2} @ \mathrm{CeO}_{2}$ but without Ce $\left(\mathrm{NO}_{3}\right)_{3} \cdot 6 \mathrm{H}_{2} \mathrm{O}$. The mass loading of EG-Ni(OH$)_{2} @ \mathrm{CeO}_{2}$, $\mathrm{Ni}(\mathrm{OH})_{2} @ \mathrm{CeO}_{2}$, and $\mathrm{Ni}(\mathrm{OH})_{2}$ supported on $\mathrm{CC}$ were $0.64,0.60$, and $0.50 \mathrm{mg} \mathrm{cm}^{-2}$, respectively.

In addition, we performed the following experiments for the synthesis of mw- $\mathrm{Ni}(\mathrm{OH})_{2} @ \mathrm{CeO}_{2}$ without EG. The prepared $\mathrm{Ni}(\mathrm{OH})_{2} @ \mathrm{CeO}_{2}$ sample was placed in a $100-\mathrm{mL}$ microwave reaction vessel containing $80 \mathrm{~mL}$ of deionized water and treated with $800 \mathrm{~W}$ microwave in a dual-control (temperature and pressure control) microwave digestion apparatus at $150^{\circ} \mathrm{C}$ for $12 \mathrm{~min}$. Upon cooling to room temperature, the finished $\mathrm{CC}$ was rinsed with ethanol to obtain mw- $\mathrm{Ni}(\mathrm{OH})_{2} @ \mathrm{CeO}_{2}$.

\section{Instrumentation and characterization}

The microstructure of the catalysts was ascertained with a Hitachi S-4800 field emission scanning electron microscope (FESEM). The crystalline structure was identified using a D8 Tools X-ray diffraction (XRD) with a voltage of $40 \mathrm{kV}$ and $30 \mathrm{~mA}$ as well as $\mathrm{Cu}-\mathrm{Ka}$ radiation $(\lambda=1.5406 \AA$ ). JEOL-2100F transmission electron microscopy (TEM) measurements were performed with an accelerating voltage of $120 \mathrm{kV}$. The atomic force microscope (AFM) was characterized by Seiko SPA400. Fourier transform infrared (FT-IR) spectra were conducted on a Bomem MB 100 FT-IR spectrometer in the wavenumber range between 400 and $4000 \mathrm{~cm}^{-1}$. X-ray photoelectron spectroscopy (XPS) analyses of the material were conducted using a Thermo Electron Model with $\mathrm{Al} \mathrm{Ka}$ as the excitation source.

\section{Electrochemical measurements}

The electrochemical performances of the materials toward OER were comprehensively evaluated with a traditional three-electrode electrolytic tank using the VMP300 Electrochemical Workstation (Bio-Logic) in $1.0 \mathrm{~mol} \mathrm{~L}^{-1} \mathrm{KOH}$. In this system, CC loaded with electrocatalyst was used as the working electrode, a saturated calomel electrode (SCE) was the reference electrode, and a Pt foil was employed as a counter electrode. Potentials were calibrated to a reversible hydrogen electrode (RHE) in Equation (1):

$E_{\mathrm{RHE}}=E_{\mathrm{SCE}}+0.242 \mathrm{~V}+0.0592 \mathrm{pH}$.

All currents presented in the graphs were normalized by the geometric surface area with $90 \% i R$ compensation. Tafel slopes were then procured from the corresponding 
linear sweep voltammetry (LSV) and chronoamperometry (CP) with a multipotential step technique. The polarization curve was recorded at $5 \mathrm{mV} \mathrm{s}^{-1}$ from 0 to $-0.7 \mathrm{~V}$ ( $v s$. SCE). The stability test was performed in $1.0 \mathrm{~mol} \mathrm{~L}^{-1} \mathrm{KOH}$ at 10,20 , and $30 \mathrm{~mA} \mathrm{~cm}^{-2}$. Electrochemical impedance spectroscopy (EIS) was detected at $300 \mathrm{mV} v s$. RHE in a frequency range from $10^{5} \mathrm{~Hz}$ to $0.1 \mathrm{MHz}$ with an alternating current (AC) potential amplitude of $10 \mathrm{mV}$.

The turnover frequency (TOF) of the electrocatalytic reaction was estimated according to the amount of $\mathrm{Ni}$ in the materials using Equation (2):

$\mathrm{TOF}=(J \times \mathrm{A}) /(4 \times F \times n)$,

where $J\left(\mathrm{~mA} \mathrm{~cm}^{-2}\right)$ is the current density at a definite overpotential, $A\left(\mathrm{~cm}^{2}\right)$ is the surface area of the electrocatalysts $\left(1 \mathrm{~cm}^{2}\right), 4$ represents the 4 electrons to generate a mole of $\mathrm{O}_{2}$ in OER, $F$ is the Faraday's constant $\left(96,485 \mathrm{C} \mathrm{mol}^{-1}\right)$, and $n$ is the number of moles of the electrochemical materials on the electrode.

\section{Computational details}

Calculations were realized in the DFT framework as implemented by the Vienna $A b$ initio Simulation Package (VASP) [42]. The exchange correlation functional was adopted employing generalized gradient approximation (GGA) with the Perdew-Burke-Ernzerhof (PBE) [43]. The slab models of $\mathrm{Ni}(\mathrm{OH})_{2}(101)$ and $\mathrm{CeO}_{2}$ (220) had thickness of $12 \AA$ and were divided by a vacuum zone of $20 \AA$. The $\mathrm{Ni}(\mathrm{OH})_{2}(101)-\mathrm{CeO}_{2}(220)$ interface had an orthogonal lattice with a maximal lattice mismatch of $4 \%$. $3 \times 3 \times 1 \mathrm{~K}$-points mesh with Monkhorst-Pack scheme was sampled in the Brillouin region. The structures were terminated when the force fulfilled $0.02 \mathrm{eV}^{-1}$ and the iterative convergence of energy was set as $10^{-5} \mathrm{eV}$. The Gibbs free energy change $(\Delta G)$ of each reaction step was calculated as Equation (3):

$\Delta G=\Delta E+\Delta \mathrm{ZPE}-T \Delta S$,

where $\Delta E$ is the adsorption energy of reaction intermediates, and $\triangle \mathrm{ZPE}$ and $\Delta S$ are the zero-point energy and entropy change between the corresponding intermediates in the former state and the latter state, respectively.

\section{RESULTS AND DISCUSSION}

With respect to the synthesis of EG-Ni(OH) $2_{2} @ \mathrm{CeO}_{2}$ nanosheets (Fig. 1a). $\mathrm{Ni}(\mathrm{acac})_{2}$ and $\mathrm{Ce}\left(\mathrm{NO}_{3}\right)_{3}$ were initially added to the methanol solution containing $n$-butylamine, and the resulting solution was treated by hydrothermal reaction for $10 \mathrm{~h}$. Then, microwave-assistant treatment was applied to the products for $12 \mathrm{~min}$ to produce the
EG-Ni(OH) $)_{2} @ \mathrm{CeO}_{2}$ nanosheets. The SEM image (Fig. S1) shows that the EG-Ni(OH)$)_{2} @ \mathrm{CeO}_{2}$ nanosheets (the size of $150 \mathrm{~nm}$ ) were uniformly attached onto the CC substrate. AFM image shows the thickness of the ultrathin nanosheets of approximately $4.3 \mathrm{~nm}$ (Fig. 1b-d). The TEM (Fig. 1e) and particle size analysis (Fig. S2) indicate that the $\mathrm{CeO}_{2}$ nanoparticles have a size of approximately $4 \mathrm{~nm}$ and are uniformly adhered to the $\mathrm{Ni}(\mathrm{OH})_{2}$ nanosheets. High resolution TEM (HRTEM) image (Fig. 2f) reveals that the $\mathrm{CeO}_{2}$ with a $0.19 \mathrm{~nm}$ plane spacing corresponds to a (220) crystal face, whereas the $\mathrm{Ni}(\mathrm{OH})_{2}$ is in a polycrystalline state with chaotic short-lattice stripes (Fig. S3). Energy dispersive X-ray spectroscopy (EDS) mappings (Fig. 1g-j) show a uniform distribution of the $\mathrm{Ni}, \mathrm{Ce}$, and $\mathrm{O}$ in the EG-Ni(OH)$)_{2} @ \mathrm{CeO}_{2}$.

The chemical constitutions of the catalysts were characterized by XRD and FT-IR (Fig. 2). The peaks of $\mathrm{Ni}(\mathrm{OH})_{2}$ are indexed to the (003), (006), (101), (110) planes (JCPDS No. 38-0715). The peaks of $28.6^{\circ}, 47.5^{\circ}$, and $56.3^{\circ}$ of the $\mathrm{CeO}_{2}$ crystal structure are according to the (111), (220), and (311) lattice planes (JCPDS No. 340394), respectively. Notably, the peak of EG-Ni(OH) $)_{2}$ $\mathrm{CeO}_{2}$ left shifts approximately $1.1^{\circ}$ due to the increasing of the interplanar spacing of (003) in comparison with $\mathrm{Ni}(\mathrm{OH})_{2} @ \mathrm{CeO}_{2}$. The reason is that the structure of the materials changes due to the adsorption of EG onto the surface of the sample during the microwave process. To verify the presence of EG in the sample, FT-IR was further introduced (Fig. 2b). After the EG treatment, the transmittance of the $-\mathrm{CH}_{2}$ vibration, the $\mathrm{O}-\mathrm{H}$ bending vibration, and $\mathrm{C}=\mathrm{O}$ stretching vibration are significantly increased, demonstrating that EG [44] does exist in the $\mathrm{EG}-\mathrm{Ni}(\mathrm{OH})_{2} @ \mathrm{CeO}_{2}$. Therefore, we prepared the EG$\mathrm{Ni}(\mathrm{OH})_{2} @ \mathrm{CeO}_{2}$ via a facile way with less energy and time consumption.

The OER activities of different catalysts were evaluated in $1.0 \mathrm{~mol} \mathrm{~L}^{-1} \mathrm{KOH}$ (Fig. 3). The small peak at $\sim 1.53 \mathrm{~V}$ is ascribed to the formation of a small amount of $\mathrm{Ni}^{4+}$ during the OER process [45]. As expected, the OER activity of $\mathrm{EG}-\mathrm{Ni}(\mathrm{OH})_{2} @ \mathrm{CeO}_{2}$ nanosheets is superior to that of $\mathrm{IrO}_{2}$. To reach $50 \mathrm{~mA} \mathrm{~cm}{ }^{-2}$, EG-Ni(OH)$)_{2} @ \mathrm{CeO}_{2}$ nanosheets merely require an overpotential of $335 \mathrm{mV}$, which is $181 \mathrm{mV}$ less than that required by $\mathrm{IrO}_{2}$ (Fig. 3c). Such overpotential is also 26 and $89 \mathrm{mV}$ less than that of $\mathrm{Ni}(\mathrm{OH})_{2} @ \mathrm{CeO}_{2}$ and $\mathrm{Ni}(\mathrm{OH})_{2}$ (Table $\left.\mathrm{S} 1\right)$. The polarization curve per unit mass in Fig. S4 also shows that the EG-Ni(OH $)_{2} @ \mathrm{CeO}_{2}$ has the best catalytic performance. Meanwhile, the OER performance of mw- Ni(OH)$)_{2} @ \mathrm{CeO}_{2}$ in Fig. S5 decreases, proving that EG has a positive effect on the OER process. Apparently, the EG-Ni(OH)${ }_{2} @ \mathrm{CeO}_{2}$ 

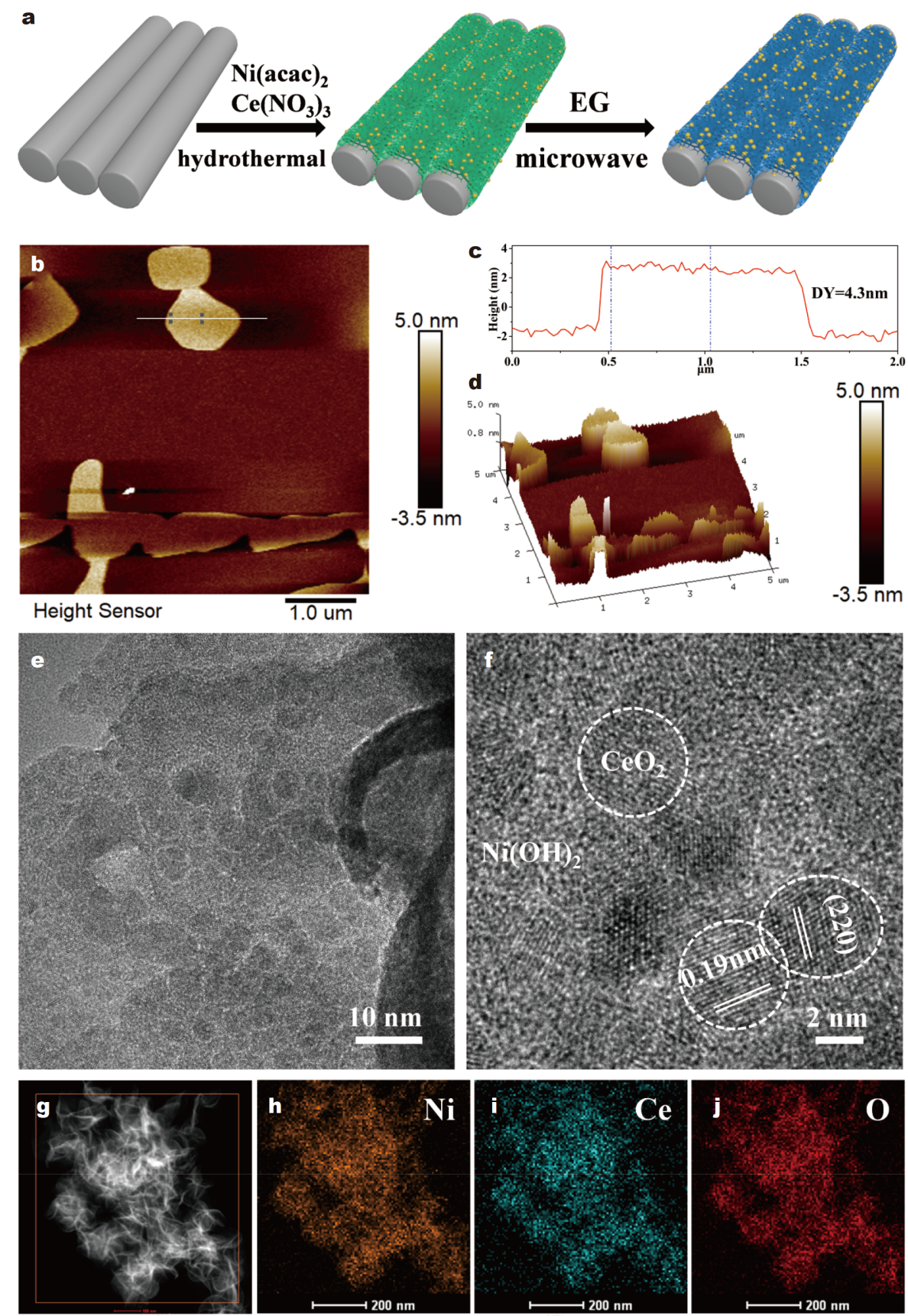

Figure 1 (a) The synthesis of EG-Ni(OH)$)_{2} @ \mathrm{CeO}_{2}$ nanosheets; (b-d) AFM images and the height profile; (e, f) TEM images; and (g-j) elemental mappings of $\mathrm{Ni}, \mathrm{Ce}$, and $\mathrm{O}$ of $\mathrm{EG}-\mathrm{Ni}(\mathrm{OH})_{2} @ \mathrm{CeO}_{2}$ nanosheets.

nanosheets possess the smallest Tafel slope $\left(67.4 \mathrm{mV} \mathrm{dec}^{-1}\right)$, which is smaller than that of $\mathrm{Ni}(\mathrm{OH})_{2} @$ $\mathrm{CeO}_{2}\left(91.1 \mathrm{mV} \mathrm{dec}^{-1}\right)$ and $\mathrm{Ni}(\mathrm{OH})_{2}\left(138.9 \mathrm{mV} \mathrm{dec}^{-1}\right)$. Thus, the reaction kinetic rate of the nickel-cerium catalyst is greatly improved under the effect of EG (Fig. 3b). The Tafel slope of the EG- $\mathrm{Ni}(\mathrm{OH})_{2} @ \mathrm{CeO}_{2}$ was further evaluated by employing the steady-state polarization curves measured by CP (Fig. S6) [46]. The as-acquired Tafel slope of the EG-Ni(OH $)_{2} @ \mathrm{CeO}_{2}$ is $69.2 \mathrm{mV} \mathrm{dec}^{-1}$, consistent with the value obtained by LSV. The Nyquist plots (Fig. 3d) reveal that the EG- $\mathrm{Ni}(\mathrm{OH})_{2} @ \mathrm{CeO}_{2}$ nanosheets possess the lowest charge transfer resistance $R_{\mathrm{ct}}$ 

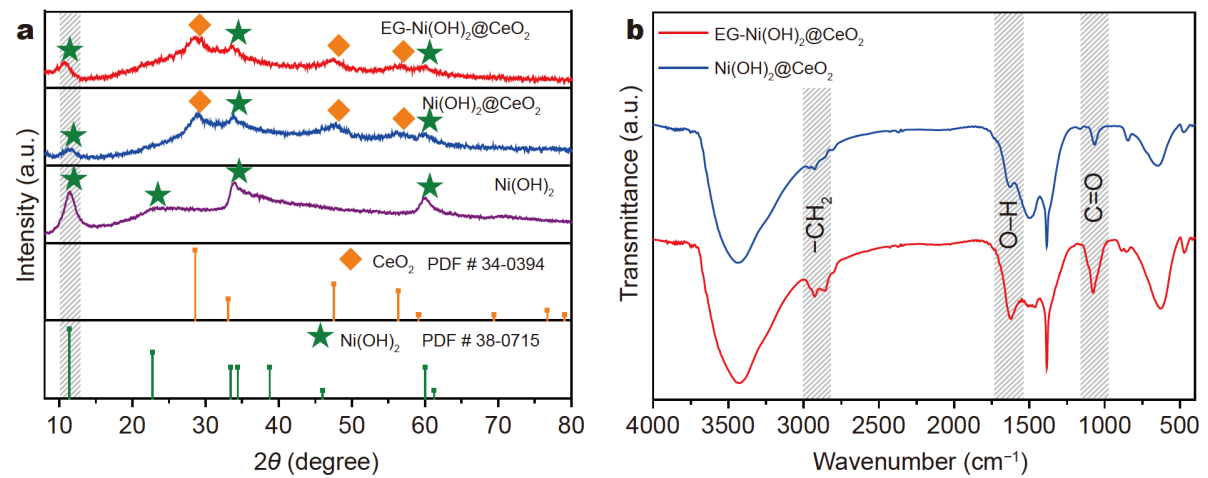

Figure 2 (a) XRD patterns of $\mathrm{Ni}(\mathrm{OH})_{2}, \mathrm{Ni}(\mathrm{OH})_{2} @ \mathrm{CeO}_{2}$, and EG-Ni(OH)$)_{2} @ \mathrm{CeO}_{2}$. (b) FT-IR spectra of $\mathrm{Ni}(\mathrm{OH})_{2} @ \mathrm{CeO}{ }_{2}$ and EG-Ni(OH) $)_{2} @ \mathrm{CeO}_{2}$.
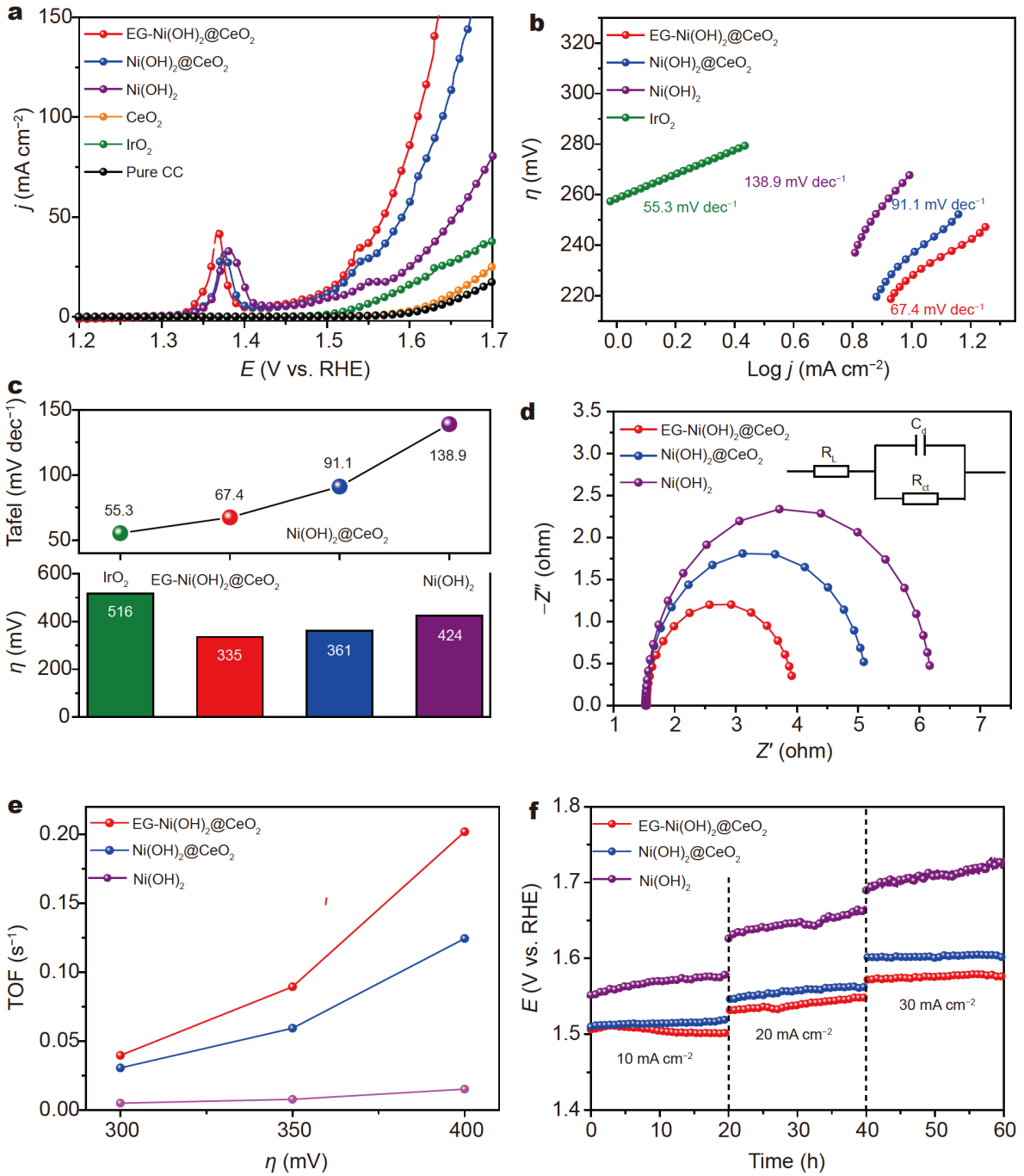

Figure 3 OER performance of the EG-Ni(OH) $)_{2} @ \mathrm{CeO}_{2}, \mathrm{Ni}(\mathrm{OH})_{2} @ \mathrm{CeO}_{2}$, and $\mathrm{Ni}(\mathrm{OH})_{2}$. (a) LSV, (b) Tafel plots, (c) comparisons of Tafel slopes (top) and overpotentials at $50 \mathrm{~mA} \mathrm{~cm}^{-2}$ (bottom), (d) fitted Nyquist plots with an equivalent circuit, (e) turnover frequency, and (f) CP curves at 10, 20, and $30 \mathrm{~mA} \mathrm{~cm}^{-2}$. 
of $2.427 \Omega$ among all catalysts. The small $R_{\text {ct }}$ values also indicate the fast electron transfer kinetics rate and enhanced conductivity. The TOF associated with $\mathrm{Ni}$ is 0.04 , 0.09 and $0.2 \mathrm{~s}^{-1}$ at the overpotentials of 300, 350 and $400 \mathrm{mV}$, respectively (Fig. 3e). The calculated Faradaic efficiency of the EG-Ni(OH) $)_{2} @ \mathrm{CeO}_{2}$ is $98 \%$ for OER in $1.0 \mathrm{~mol} \mathrm{~L}^{-1} \mathrm{KOH}$ (Fig. S7). Stability is an indispensable feature for a comparable catalyst. The long-time stability test was conducted at 10,20, and $30 \mathrm{~mA} \mathrm{~cm}^{-2}$ (Fig. 3f). The potential loss under these current densities can be negligible after $60 \mathrm{~h}$. Moreover, little morphology and structure changes (Figs S8-S11) were observed after $20 \mathrm{~h}$ under $10 \mathrm{~mA} \mathrm{~cm}^{-2}$, suggesting the comparable stability of the EG-Ni(OH)$)_{2} @ \mathrm{CeO}_{2}$ nanosheets. Meanwhile, Fig. S12 shows that the residual EG during OER process is stable.

To investigate the OER mechanism on EG-Ni(OH) $)_{2}$ $\mathrm{CeO}_{2}$ nanosheets, XPS was used to analyze the surface electron states of the EG-Ni(OH)$)_{2} @ \mathrm{CeO}_{2}$. The elemental composition of EG-Ni(OH)$)_{2} @ \mathrm{CeO}_{2}$, including $\mathrm{Ni}, \mathrm{Ce}$, and $\mathrm{O}$, was further confirmed by using full measurement scan XPS spectra (Fig. S13). Compared with $\mathrm{Ni}(\mathrm{OH})_{2}$, the $\mathrm{Ni} 2 \mathrm{p}$ spectrum of $\mathrm{Ni}(\mathrm{OH})_{2} @ \mathrm{CeO}_{2}$ shifts $\sim 0.18 \mathrm{eV}$ to the lower binding energy (Fig. 4a) and corresponds to the change of the chemical state of $\mathrm{Ni}$ from a high-valence
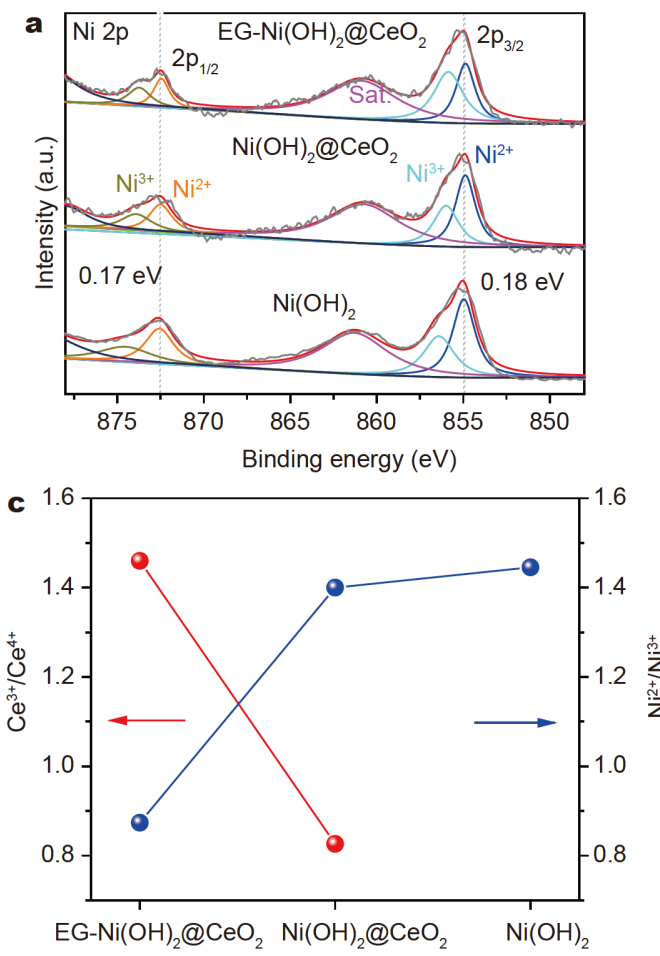

$\left(\mathrm{Ni}^{3+}\right)$ to a low-valence state $\left(\mathrm{Ni}^{(3-\delta)+}\right)$, thereby indicating a strong electron interaction between $\mathrm{Ni}(\mathrm{OH})_{2}$ and $\mathrm{CeO}_{2}$ [47]. Then the presence of EG ligand lowers the calculated molar ratio of $\mathrm{Ni}^{2+} / \mathrm{Ni}^{3+}$ from 1.4 to 0.87 (Fig. $4 \mathrm{c}$, blue). This result suggests that the EG-Ni(OH)$)_{2} @ \mathrm{CeO}_{2}$ has the highest $\mathrm{Ni}^{3+}$ concentration and the nickel-cerium interface is further optimized to produce more $\mathrm{Ni}^{(3-\delta)+}$ active sites under the EG environment, consequently facilitating the rapid progress of the OER reaction. Hence, the adsorption of EG leads to a decrease in the ratio of $\mathrm{Ni}^{2+} / \mathrm{Ni}^{3+}$ in $\mathrm{Ni}(\mathrm{OH})_{2}$, the ionic radius of $\mathrm{Ni}^{3+}$ is smaller than that of $\mathrm{Ni}^{2+}$ and the interplanar spacing of (003) increases, which is consistent with the XRD results (Fig. 2a). The Ce consists of $3 \mathrm{~d}_{5 / 2}$ and $3 \mathrm{~d}_{3 / 2}$ spin-orbit [48] (Fig. 4b). The Ce $3 \mathrm{~d}$ spectra were fitted into eight peaks, and the change in the peak area revealed that the $\mathrm{Ce}^{3+}$ concentration greatly increased after EG treatment. Concretely, the calculated molar ratio of $\mathrm{Ce}^{3+} / \mathrm{Ce}^{4+}$ changes from 0.83 to 1.46 according to the $v^{\prime} / v^{\prime \prime}$ and $u^{\prime} / u^{\prime \prime}$ (Fig. 4c, red). Combined with $\mathrm{O}$ 1s spectra of $\mathrm{Ni}(\mathrm{OH})_{2} @ \mathrm{CeO}_{2}, \mathrm{Ni}(\mathrm{OH})_{2}$, and $\mathrm{CeO}_{2}$ before and after EG treatment, the $\mathrm{Ce}-\mathrm{O}$ peak at $\sim 529.5 \mathrm{eV}$ was weakened in $\mathrm{Ni}(\mathrm{OH})_{2} @ \mathrm{CeO}_{2}$ and $\mathrm{CeO}_{2}$ after EG treatment, and no significant metal-oxygen peak was found in $\mathrm{Ni}(\mathrm{OH})_{2}$
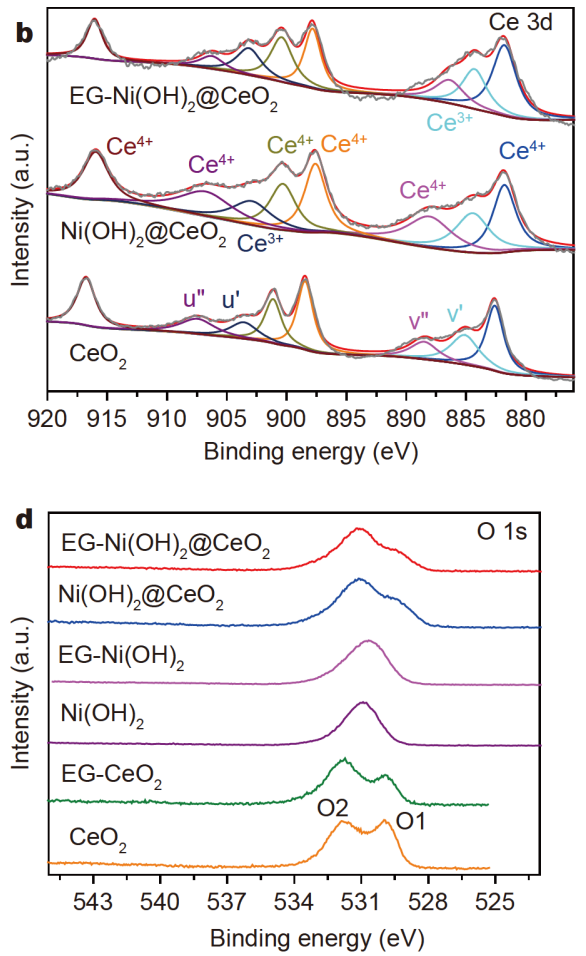

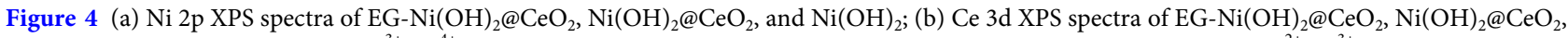
and $\mathrm{CeO}_{2}$; (c) molar ratios of $\mathrm{Ce}^{3+} / \mathrm{Ce}^{4+}$ (red) of the $\mathrm{EG}-\mathrm{Ni}(\mathrm{OH})_{2} @ \mathrm{CeO}_{2}, \mathrm{Ni}(\mathrm{OH})_{2} @ \mathrm{CeO}_{2}$ and molar ratios of $\mathrm{Ni}^{2+} / \mathrm{Ni}^{3+}(\mathrm{blue})$ of the $\mathrm{EG}-$ $\mathrm{Ni}(\mathrm{OH})_{2} @ \mathrm{CeO}_{2}, \mathrm{Ni}(\mathrm{OH})_{2} @ \mathrm{CeO}_{2}, \mathrm{Ni}(\mathrm{OH})_{2} ;$ (d) $\mathrm{O}$ 1s XPS of different catalysts. 
(Fig. 4d) [49]. EG was preferentially adsorbed onto the $\mathrm{CeO}_{2}$, thereby affecting the electronic state of the $\mathrm{CeO}_{2}$ from $\mathrm{Ce}^{4+}$ to $\mathrm{Ce}^{3+}$, and further increasing the concentration of $\mathrm{Ni}^{(3-\delta)+}$ in the $\mathrm{EG}-\mathrm{Ni}(\mathrm{OH})_{2} @ \mathrm{CeO}_{2}$ via electron transport effect.

To further understand the intrinsic effect, the electrocatalytic processes were studied to check the interfacial effect on the OER. The four main sequential steps of OER in alkaline conditions were explored [50]:

$\mathrm{OH}^{-}+* \rightarrow \mathrm{OH}^{*}+\mathrm{e}^{-}$,

$\mathrm{OH}^{*}+\mathrm{OH}^{-} \rightarrow \mathrm{O}^{*}+\mathrm{H}_{2} \mathrm{O}+\mathrm{e}^{-}$,

$\mathrm{O}^{*}+\mathrm{OH}^{-} \rightarrow \mathrm{HOO}^{*}+\mathrm{e}^{-}$,

$\mathrm{OOH}^{*}+\mathrm{OH}^{-} \rightarrow *+\mathrm{O}_{2}+\mathrm{H}_{2} \mathrm{O}+\mathrm{e}^{-}$,

where * represents the element of the surface reaction sites. For the Ni-base catalysts, $\mathrm{Ni}^{3+}$ is commonly considered to be the most catalytic site in the OER process $[40,51]$. However, $\mathrm{Ni}^{3+}$ has a strong adsorption capacity for $\mathrm{O}^{*}$ and is not conducive to the continued production of $\mathrm{OOH}^{*}[52,53]$. So the potential determining step (PDS) occurs at the intermediate $\mathrm{O}^{*}$ species. The construction of the nickel-cerium interface results in electron transfer from cerium to nickel to produce $\mathrm{Ni}^{(3-\delta)+}$ at the interface, and such transfer is beneficial for weakening the adsorption of the Ni site to the $\mathrm{O} *$ intermediate. For the electrocatalytic water oxidation, one obvious oxidation process attributed to the $\mathrm{Ni}^{2+} \leftrightarrow \mathrm{Ni}^{3+}$ (ca. $1.37 \mathrm{~V} v$ s. RHE in Fig. 5a) in the cyclic voltammetry (CV) plots was detected. Note that increased oxidation peak current due to the adsorption of the EG ligand results in the conversion of more $\mathrm{Ni}^{2+}$ to $\mathrm{Ni}^{3+}$ in the electrochemical reaction of the EG-Ni(OH $)_{2} @ \mathrm{CeO}_{2}$, and this development is more favorable for the OER catalytic reaction.

DFT calculations were also implemented to further examine the microscopic mechanism of OER enhancement on the EG-Ni(OH $)_{2} @ \mathrm{CeO}_{2}$. The optimized structures of the EG-Ni(OH $)_{2} @ \mathrm{CeO}_{2}, \mathrm{Ni}(\mathrm{OH})_{2} @ \mathrm{CeO}_{2}$, and $\mathrm{Ni}(\mathrm{OH})_{2}$ were presented in Figs S14-S16, respectively. A reaction mechanism is depicted in Fig. $5 \mathrm{c}$. In the case of EG-Ni(OH $)_{2} @ \mathrm{CeO}_{2}$, one free hydroxide ion was adsorbed onto the exposed $\mathrm{Ni}$ site, and proceeded through the formation of $\mathrm{OH}^{*}, \mathrm{O}^{*}$, and $\mathrm{OOH}^{*}$ intermediates and finally accelerated the $\mathrm{O}_{2}$ production. From the view on free-energy changes of the intermediates for different catalysts, the energy-change lines under the catalytic roles of the EG- $\mathrm{Ni}(\mathrm{OH})_{2} @ \mathrm{CeO}_{2}$ showed that the free-energy barriers of the EG-Ni(OH) $@ \mathrm{CeO}_{2}$ was much lower than
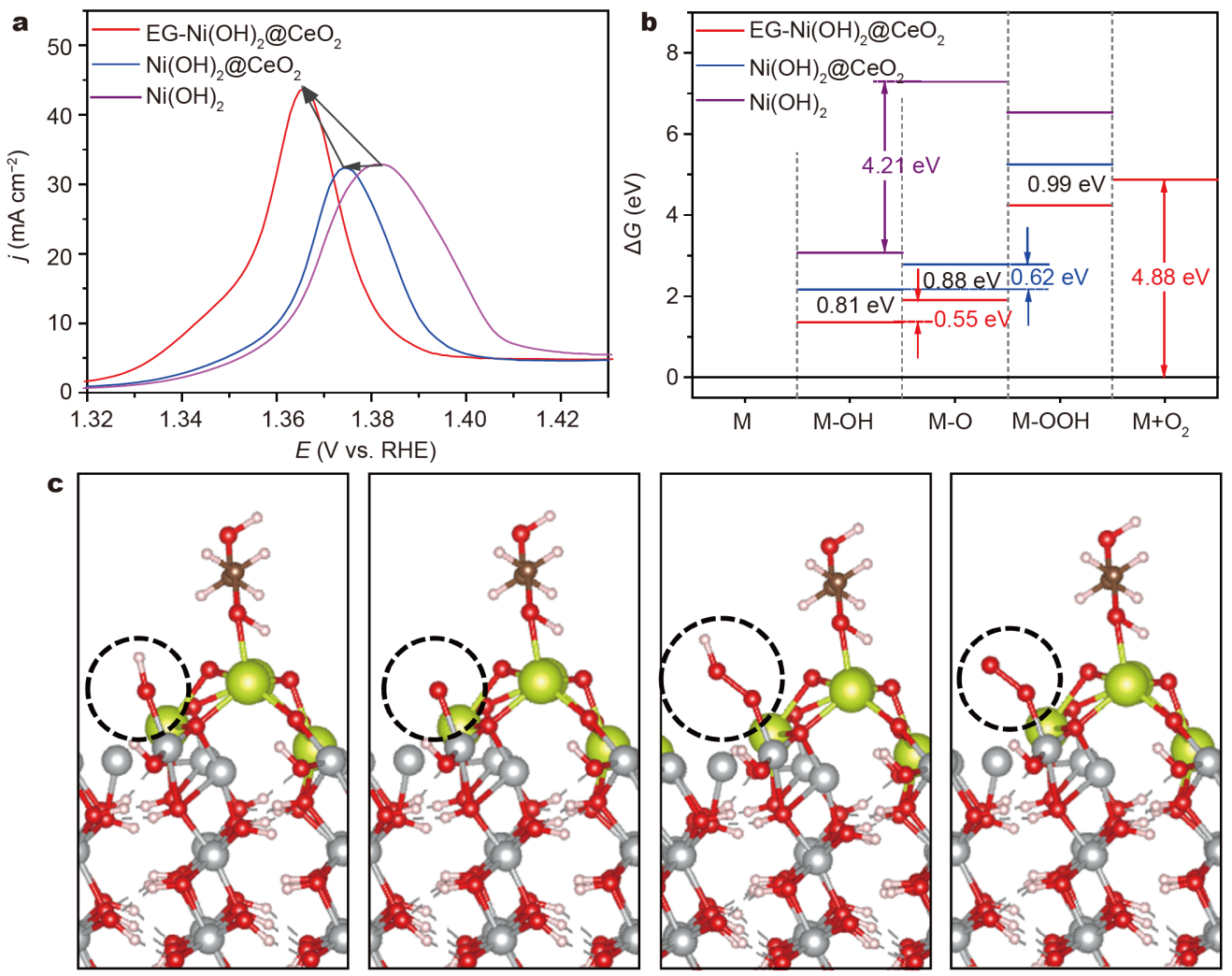

Figure 5 (a) Oxidation peak of the CV curves; (b) free energy diagram for OER of the $\mathrm{EG}-\mathrm{Ni}(\mathrm{OH})_{2} @ \mathrm{CeO}{ }_{2}, \mathrm{Ni}(\mathrm{OH})_{2} @ \mathrm{CeO}{ }_{2}$, and $\mathrm{Ni}(\mathrm{OH})_{2} .(\mathrm{c})$ Proposed mechanism of $\mathrm{O}_{2}$ evolution over the EG-Ni(OH)$)_{2} @ \mathrm{CeO}_{2}$. 
that of $\mathrm{Ni}(\mathrm{OH})_{2} @ \mathrm{CeO}_{2}$ and $\mathrm{Ni}(\mathrm{OH})_{2}$ (Fig. 5b). Specifically, the barriers of $\mathrm{O}^{*}$ intermediate PDS are $0.55,0.62$, and $4.21 \mathrm{eV}$ for EG-Ni(OH)$)_{2} @ \mathrm{CeO}_{2}, \mathrm{Ni}(\mathrm{OH})_{2} @ \mathrm{CeO}_{2}$, and $\mathrm{Ni}(\mathrm{OH})_{2}$, respectively. Thus, the EG- $\mathrm{Ni}(\mathrm{OH})_{2} @ \mathrm{CeO}_{2}$ has the lowest energy reaction barrier and the fastest reaction kinetic rate.

Given the above DFT calculations and control experiments, doping EG-adsorbed $\mathrm{CeO}_{2}$ reduces the reaction barrier in the entire OER reaction. During this process, the mechanism of EG-adsorbed $\mathrm{CeO}_{2}$ optimized the electronic valence of the $\mathrm{Ni}$ site and the OER performance of the EG-Ni(OH) $2_{2} @ \mathrm{CeO}_{2}$ was improved (Fig. 6). On the basis of the presence of $\mathrm{Ni}^{(3-\delta)+}$ at the nickel-ceria interface, the amount of $\mathrm{Ni}^{(3-\delta)+}$ active sites was increased by adsorbing EG ligands, increasing the overall kinetic rate of the OER catalytic reaction. Therefore, the OER electrocatalytic activity of nickel hydroxide nanosheets is improved by the tuning of the EG-adsorbed $\mathrm{CeO}_{2}$.

\section{CONCLUSION}

To sum up, the novel material EG- $\mathrm{Ni}(\mathrm{OH})_{2} @ \mathrm{CeO}_{2}$ grown on CC was developed and used as high-efficiency catalysts for OER. The EG-Ni(OH $)_{2} @ \mathrm{CeO}_{2}$ enabled high performance with a low overpotential $(335 \mathrm{mV})$ to reach $50 \mathrm{~mA} \mathrm{~cm}^{-2}$, a Tafel slope $\left(67.4 \mathrm{mV} \mathrm{dec}^{-1}\right)$ and compar-

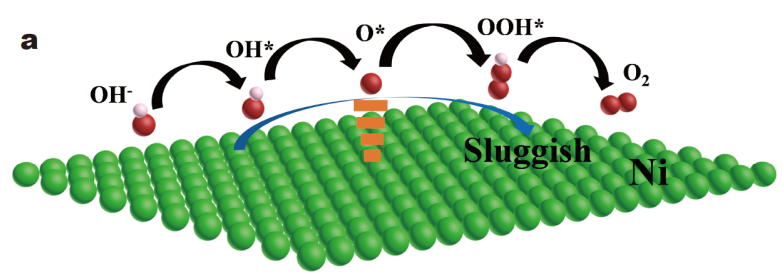

b

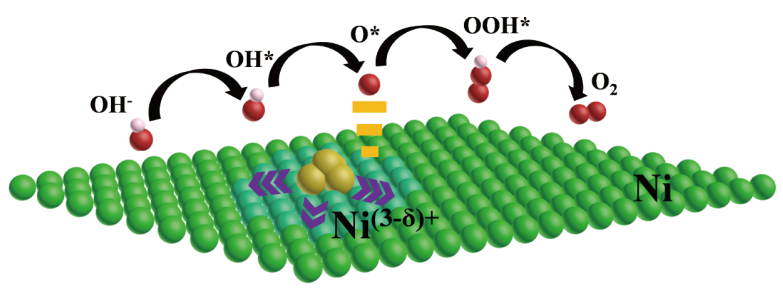

C

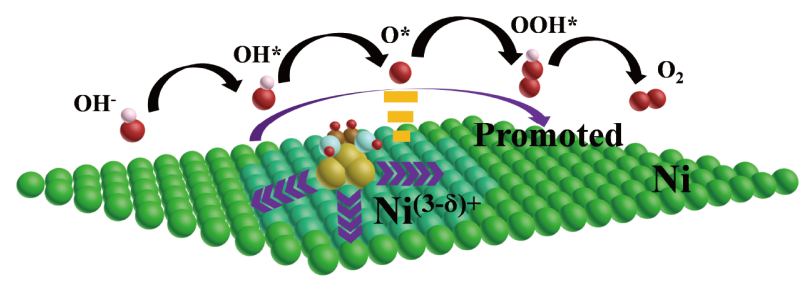

Figure 6 OER processes with different catalysts: (a) $\mathrm{Ni}(\mathrm{OH})_{2}$ (b) $\mathrm{Ni}(\mathrm{OH})_{2} @ \mathrm{CeO}_{2}$, and (c) EG- $\mathrm{Ni}(\mathrm{OH})_{2} @ \mathrm{CeO}_{2}$. able long-term durability toward OER. Characterization and theoretical calculations confirmed that the excellent performance of EG-Ni(OH $)_{2} @ \mathrm{CeO}_{2}$ could be attributed to EG-adsorbed $\mathrm{CeO}_{2}$ controlling the electronic state of $\mathrm{Ni}(\mathrm{OH})_{2}$, which greatly increased the concentration of $\mathrm{Ni}^{(3-\delta)+}$ and reduced the reaction barrier in the OER catalytic process. This work reveals the effect of EG ligands on the catalytic interface, and provides some inspiration for interface material construction under an organic ligand environment.

Received 9 February 2020; accepted 3 April 2020;

published online 20 May 2020

1 Kuang Y, Kenney MJ, Meng Y, et al. Solar-driven, highly sustained splitting of seawater into hydrogen and oxygen fuels. Proc Natl Acad Sci USA, 2019, 116: 6624-6629

2 Li Y, Zhou W, Wang $\mathrm{H}$, et al. An oxygen reduction electrocatalyst based on carbon nanotube-graphene complexes. Nat Nanotech, 2012, 7: 394-400

3 Novoselov KS, Mishchenko A, Carvalho A, et al. 2D materials and van der Waals heterostructures. Science, 2016, 353: aac9439

4 Merkl P, Mooshammer F, Steinleitner P, et al. Ultrafast transition between exciton phases in van der Waals heterostructures. Nat Mater, 2019, 18: 691-696

5 Ahn SH, Manthiram A. Hierarchical tri-functional electrocatalysts derived from bimetallic-imidazolate framework for overall water splitting and rechargeable zinc-air batteries. J Mater Chem A, 2019, 7: 8641-8652

6 Liu P, Xiang B. 2D hetero-structures based on transition metal dichalcogenides: Fabrication, properties and applications. Sci Bull, 2017, 62: 1148-1161

7 Huang ZF, Song J, Du Y, et al. Chemical and structural origin of lattice oxygen oxidation in Co-Zn oxyhydroxide oxygen evolution electrocatalysts. Nat Energy, 2019, 4: 329-338

8 Bajdich M, García-Mota M, Vojvodic A, et al. Theoretical investigation of the activity of cobalt oxides for the electrochemical oxidation of water. J Am Chem Soc, 2013, 135: 13521-13530

9 Mondschein JS, Callejas JF, Read CG, et al. Crystalline cobalt oxide films for sustained electrocatalytic oxygen evolution under strongly acidic conditions. Chem Mater, 2017, 29: 950-957

10 Kumari S, Ajayi BP, Kumar B, et al. A low-noble-metal $\mathrm{W}_{1-x} \mathrm{Ir}_{x} \mathrm{O}_{3-\delta}$ water oxidation electrocatalyst for acidic media via rapid plasma synthesis. Energy Environ Sci, 2017, 10: 2432-2440

11 Zhang Y, Ouyang B, Xu J, et al. Rapid synthesis of cobalt nitride nanowires: Highly efficient and low-cost catalysts for oxygen evolution. Angew Chem Int Ed, 2016, 55: 8670-8674

12 Qian Q, Li Y, Liu Y, et al. Ambient fast synthesis and active sites deciphering of hierarchical foam-like trimetal-organic framework nanostructures as a platform for highly efficient oxygen evolution electrocatalysis. Adv Mater, 2019, 31: 1901139

$13 \mathrm{Lu} \mathrm{Y}$, Fan D, Chen $\mathrm{Z}$, et al. Anchoring $\mathrm{Co}_{3} \mathrm{O}_{4}$ nanoparticles on MXene for efficient electrocatalytic oxygen evolution. Sci Bull, 2020, 65: 460-466

14 Chen J, Zheng F, Zhang SJ, et al. Interfacial interaction between $\mathrm{FeOOH}$ and $\mathrm{Ni}$-Fe LDH to modulate the local electronic structure for enhanced OER electrocatalysis. ACS Catal, 2018, 8: 1134211351 
15 Zhang T, Liao SA, Dai LX, et al. Ir-Pd nanoalloys with enhanced surface-microstructure-sensitive catalytic activity for oxygen evolution reaction in acidic and alkaline media. Sci China Mater, 2018, 61: 926-938

16 Zhao L, Cao Q, Wang A, et al. Iron oxide embedded titania nanowires-An active and stable electrocatalyst for oxygen evolution in acidic media. Nano Energy, 2018, 45: 118-126

17 Cai $\mathrm{Z}, \mathrm{Bu} \mathrm{X}$, Wang $\mathrm{P}$, et al. Recent advances in layered double hydroxide electrocatalysts for the oxygen evolution reaction. J Mater Chem A, 2019, 7: 5069-5089

18 Zhao JQ, Cai D, Dai J, et al. Heptanuclear brucite disk with cyanide bridges in a cocrystal and tracking its pyrolysis to an efficient oxygen evolution electrode. Sci Bull, 2019, 64: 1667-1674

19 Ding J, Shao Q, Feng Y, et al. Ruthenium-nickel sandwiched nanoplates for efficient water splitting electrocatalysis. Nano Energy, 2018, 47: 1-7

20 Luo X, Wei X, Zhong $\mathrm{H}$, et al. Single-atom Ir-anchored 3D amorphous NiFe nanowire@nanosheets for boosted oxygen evolution reaction. ACS Appl Mater Interfaces, 2020, 12: 3539-3546

21 Wang Y, Qiao M, Li Y, et al. Tuning surface electronic configuration of NiFe LDHs nanosheets by introducing cation vacancies ( $\mathrm{Fe}$ or $\mathrm{Ni}$ ) as highly efficient electrocatalysts for oxygen evolution reaction. Small, 2018, 14: 1800136

22 Ma W, Ma R, Wang C, et al. A superlattice of alternately stacked $\mathrm{Ni}-\mathrm{Fe}$ hydroxide nanosheets and graphene for efficient splitting of water. ACS Nano, 2015, 9: 1977-1984

23 Zhan C, Liu Z, Zhou Y, et al. Triple hierarchy and double synergies of $\mathrm{NiFe} / \mathrm{Co}_{9} \mathrm{~S}_{8} /$ carbon cloth: a new and efficient electrocatalyst for the oxygen evolution reaction. Nanoscale, 2019, 11: 3378-3385

24 Guo D, Chen F, Zhang W, et al. Phase-transfer synthesis of $\alpha$ $\mathrm{Co}(\mathrm{OH})_{2}$ and its conversion to $\mathrm{CoO}$ for efficient electrocatalytic water oxidation. Sci Bull, 2017, 62: 626-632

25 Wang $\mathrm{H}$, Casalongue HS, Liang $\mathrm{Y}$, et al. $\mathrm{Ni}(\mathrm{OH})_{2}$ nanoplates grown on graphene as advanced electrochemical pseudocapacitor materials. J Am Chem Soc, 2010, 132: 7472-7477

26 Kong X, Zhang C, Hwang SY, et al. Free-standing holey $\mathrm{Ni}(\mathrm{OH})_{2}$ nanosheets with enhanced activity for water oxidation. Small, 2017, 13: 1700334

27 Hussain N, Yang W, Dou J, et al. Ultrathin mesoporous F-doped $\alpha-\mathrm{Ni}(\mathrm{OH})_{2}$ nanosheets as an efficient electrode material for water splitting and supercapacitors. J Mater Chem A, 2019, 7: 9656-9664

28 Zhang S, Lv F, Zhang X, et al. Ni@RuM ( $\mathrm{M}=\mathrm{Ni}$ or Co) core@shell nanocrystals with high mass activity for overall water-splitting catalysis. Sci China Mater, 2019, 62: 1868-1876

29 Liu X, Ni K, Wen B, et al. Deep reconstruction of nickel-based precatalysts for water oxidation catalysis. ACS Energy Lett, 2019, 4: 2585-2592

30 Du L, Luo L, Feng Z, et al. Nitrogen-doped graphitized carbon shell encapsulated NiFe nanoparticles: A highly durable oxygen evolution catalyst. Nano Energy, 2017, 39: 245-252

$31 \mathrm{Wu}$ Y, Liu X, Han D, et al. Electron density modulation of $\mathrm{NiCo}_{2} \mathrm{~S}_{4}$ nanowires by nitrogen incorporation for highly efficient hydrogen evolution catalysis. Nat Commun, 2018, 9: 1425

32 Yan J, Chen L, Liang X. $\mathrm{Co}_{9} \mathrm{~S}_{8}$ nanowires@NiCo LDH nanosheets arrays on nickel foams towards efficient overall water splitting. Sci Bull, 2019, 64: 158-165

33 An L, Feng J, Zhang Y, et al. Epitaxial heterogeneous interfaces on $\mathrm{N}-\mathrm{NiMoO}_{4} / \mathrm{NiS}_{2}$ nanowires/nanosheets to boost hydrogen and oxygen production for overall water splitting. Adv Funct Mater, 2019, 29: 1805298
34 Cao J, Zhou J, Zhang Y, et al. Dominating role of aligned $\mathrm{MoS}_{2} /$ $\mathrm{Ni}_{3} \mathrm{~S}_{2}$ nanoarrays supported on three-dimensional $\mathrm{Ni}$ foam with hydrophilic interface for highly enhanced hydrogen evolution reaction. ACS Appl Mater Interfaces, 2018, 10: 1752-1760

35 Gao W, Xia Z, Cao F, et al. Comprehensive understanding of the spatial configurations of $\mathrm{CeO}_{2}$ in $\mathrm{NiO}$ for the electrocatalytic oxygen evolution reaction: Embedded or surface-loaded. Adv Funct Mater, 2018, 28: 1706056

$36 \mathrm{Xu} \mathrm{H}$, Wang B, Shan C, et al. Ce-doped NiFe-layered double hydroxide ultrathin nanosheets/nanocarbon hierarchical nanocomposite as an efficient oxygen evolution catalyst. ACS Appl Mater Interfaces, 2018, 10: 6336-6345

37 Kaneko H, Tamaura Y. Reactivity and XAFS study on $(1-x) \mathrm{CeO}_{2-x} \mathrm{NiO}(x=0.025-0.3)$ system in the two-step watersplitting reaction for solar $\mathrm{H}_{2}$ production. J Phys Chem Solids, 2009, 70: 1008-1014

38 Zheng X, Cao Y, Han X, et al. Pt embedded $\mathrm{Ni}_{3} \mathrm{Se}_{2} @ \mathrm{NiOOH}$ coreshell dendrite-like nanoarrays on nickel as bifunctional electrocatalysts for overall water splitting. Sci China Mater, 2019, 62: 1096-1104

39 Yuan Q, Yu Y, Gong Y, et al. Three-dimensional N-doped carbon nanotube frameworks on $\mathrm{Ni}$ foam derived from a metal-organic framework as a bifunctional electrocatalyst for overall water splitting. ACS Appl Mater Interfaces, 2020, 12: 3592-3602

40 Zhao D, Pi Y, Shao Q, et al. Enhancing oxygen evolution electrocatalysis via the intimate hydroxide-oxide interface. ACS Nano, 2018, 12: 6245-6251

41 Wang $\mathrm{P}$, Yan M, Meng J, et al. Oxygen evolution reaction dynamics monitored by an individual nanosheet-based electronic circuit. Nat Commun, 2017, 8: 645

42 Momma K, Izumi F. VESTA 3 for three-dimensional visualization of crystal, volumetric and morphology data. J Appl Crystlogr, 2011, 44: 1272-1276

43 Perdew JP, Burke K, Ernzerhof M. Generalized gradient approximation made simple. Phys Rev Lett, 1996, 77: 3865-3868

44 Li J, Liu HX, Gou W, et al. Ethylene-glycol ligand environment facilitates highly efficient hydrogen evolution of $\mathrm{Pt} / \mathrm{CoP}$ through proton concentration and hydrogen spillover. Energy Environ Sci, 2019, 12: 2298-2304

45 Trotochaud L, Young SL, Ranney JK, et al. Nickel-iron oxyhydroxide oxygen-evolution electrocatalysts: The role of intentional and incidental iron incorporation. J Am Chem Soc, 2014, 136: 6744-6753

46 Yu M, Zhou S, Wang Z, et al. Boosting electrocatalytic oxygen evolution by synergistically coupling layered double hydroxide with MXene. Nano Energy, 2018, 44: 181-190

47 Liu Z, Li N, Zhao $\mathrm{H}$, et al. Regulating the active species of $\mathrm{Ni}(\mathrm{OH})_{2}$ using $\mathrm{CeO}_{2}: 3 \mathrm{D} \mathrm{CeO} / \mathrm{Ni}(\mathrm{OH})_{2} /$ carbon foam as an efficient electrode for the oxygen evolution reaction. Chem Sci, 2017, 8: 32113217

48 Feng JX, Ye SH, Xu H, et al. Design and synthesis of $\mathrm{FeOOH} / \mathrm{CeO}_{2}$ heterolayered nanotube electrocatalysts for the oxygen evolution reaction. Adv Mater, 2016, 28: 4698-4703

49 Huang W, Cao Y, Chen Y, et al. Fast synthesis of porous $\mathrm{NiCo}_{2} \mathrm{O}_{4}$ hollow nanospheres for a high-sensitivity non-enzymatic glucose sensor. Appl Surf Sci, 2017, 396: 804-811

50 Yan J, Kong L, Ji Y, et al. Single atom tungsten doped ultrathin $\alpha$ $\mathrm{Ni}(\mathrm{OH})_{2}$ for enhanced electrocatalytic water oxidation. Nat Commun, 2019, 10: 2149

51 Govind Rajan A, Martirez JMP, Carter EA. Facet-independent 
oxygen evolution activity of pure $\beta-\mathrm{NiOOH}$ : Different chemistries leading to similar overpotentials. J Am Chem Soc, 2020, 142: 36003612

52 Friebel D, Louie MW, Bajdich M, et al. Identification of highly active $\mathrm{Fe}$ sites in $(\mathrm{Ni}, \mathrm{Fe}) \mathrm{OOH}$ for electrocatalytic water splitting. J Am Chem Soc, 2015, 137: 1305-1313

53 Rossmeisl J, Qu ZW, Zhu H, et al. Electrolysis of water on oxide surfaces. J Electroanal Chem, 2007, 607: 83-89

Acknowledgements This research was financially supported by the National Natural Science Foundation of China (51762012 and 51862006), the Key Research and Development Project of Hainan Province (ZDYF2018106), and the Research Unit of Island Emergency Medicine of Chinese Academy of Medical Sciences (2019RU013).

Author contributions Z Zhan $C$ designed the experiments and wrote the paper with the support from Tu J; Yu Z and Liu Z performed the experiments; Zhan $\mathrm{C}$ and Chen $\mathrm{D}$ conducted the performance tests; Chen $\mathrm{Y}$ and $\mathrm{Wu} \mathrm{Q}$ performed the data analysis; Zhang X contributed to the theoretical analysis; Cao Y supervised the research. All authors discussed the results and commented on the manuscript.

Conflict of interest The authors declare no conflict of interest.

Supplementary information Experimental details and supporting data are available in the online version of the paper.

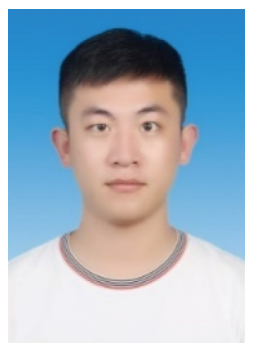

Changhong Zhan received his BSc degree from Hainan University in 2017. Now he is pursuing his master degree in materials science and engineering at Hainan University. His current research interests focus on non-noble metal-based catalysts for electrochemical applications.

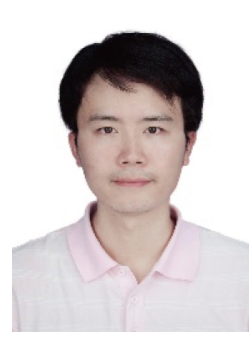

Jinchun $\mathrm{Tu}$ is a professor in the College of Materials Sciences at Hainan University. His research interests focus on the design of photoelectric materials and interface electron transport process.

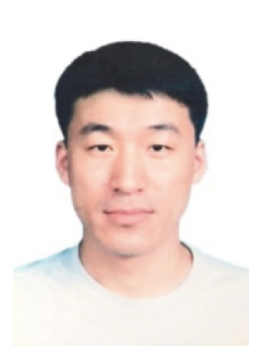

Qiang Wu is currently a professor of Hainan Medical University. His research fields mainly involve new techniques of molecular diagnosis, biosensor and the design of point-of-care testing (POCT) devices.

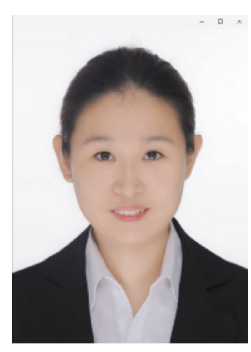

Xiaolin Zhang received her $\mathrm{PhD}$ degree in materials physics and chemistry from Jilin University in 2018. Now she is a lecturer in Qiongtai Normal University. Her current research interest is in modifying electrodes for biosensors and electrochemical catalysis.

\section{通过构建乙二醇配体环境有效优化镍-铈界面以 加速水氧化反应动力学}

战长宏 ${ }^{1}$, 于子嘉, 刘铮 ${ }^{1}$, 陈永 $^{1}$, 陈德伦 ${ }^{1}$, 涂进春 ${ }^{1 *}$, 邬强 ${ }^{2}$, 张晓琳 ${ }^{3^{*}}$, 曹阳 ${ }^{1,3}$

摘要 析氧反应 $(\mathrm{OER})$ 作为获得高效稳定水裂解的半反应, 是一个 涉及四电子 $\left(4 \mathrm{e}^{-}\right)$转移过程的缓慢动力学过程, 因此需要催化剂加 快电子转移速率以促进反应进行. 本文利用乙二醇配体的吸附作 用优化二氧化铈纳米颗粒和氢氧化镍纳米片构建的界面材料(EG$\left.\mathrm{Ni}(\mathrm{OH})_{2} @ \mathrm{CeO}_{2}\right)$. 分析表征和密度泛函理论(DFT)证明, 乙二醇诱 导的镍-铈界面具有很强的电子相互作用, 产生了大量的 $\mathrm{Ni}^{(3-\delta)+}$ 活 性位点, 降低了反应势垒, 并促进了催化体系中的电子传输动力学. EG- $\mathrm{Ni}(\mathrm{OH})_{2} @ \mathrm{CeO}_{2}$ 具有出色的OER性能, 在 $50 \mathrm{~mA} \mathrm{~cm}^{-2}$ 下表现出 $335 \mathrm{mV}$ 的过电位和 $67.4 \mathrm{~m} \mathrm{~V} \mathrm{dec}^{-1}$ 的 Tafel斜率. 在 $10 、 20$ 和 $30 \mathrm{~mA} \mathrm{~cm}^{-2}$ 下可保持 $60 \mathrm{~h}$ 稳定. 本研究表明基于有机溶剂吸附的金 属材料界面工程对改善电催化OER工艺的重要性. 